\title{
Audit in general practice: students and practitioners learning together
}

Peter Campion, Ian Stanley, Maxine Haddleton

\begin{abstract}
Objectives - To describe and evaluate the use of medical audit in general practice as an educational activity shared by undergraduate medical students and general practitioners.
\end{abstract}

Design - A descriptive study, evaluated by a questionnaire survey of all participating practices and by results of completed student projects on general practice audit topics during three weeks in the first year of completed projects (1990-1).

Setting - One university department of general practice, collaborating with 18 general practices in contract with Liverpool Family Health Services Authority.

Participants - 150 medical students, working in groups of two to six, and the general practitioners with whom they worked in 18 practices.

Main measures - The nature of topics proposed by practices and chosen by the students; methods of audit used by students; reported effects of the audits on the practices; general practitioners' opinions of the projects' usefulness to the practice.

Results - The range of topics was wide, and both quantitative and qualitative methods were used. Fifteen of the 18 questionnaires sent out were completed. Six practices reported that the final project had changed substantially after joint planning with the students. Two thirds (10) attached high value to the audits and were making changes in the delivery of care as a result.

Conclusions - Medical audit "project work" by medical undergraduates is an effective tool for motivating students to learn and can lead to change in the clinical setting in which it occurs.

Implications - By meeting the learning needs of both undergraduates and established practitioners audit project work has wider application within medical education.

(Quality in Health Care 1992;1:114-118)

\section{Introduction}

Recently medical audit has been fostered by the Department of Health (DOH) ${ }^{1}$ as a means of "quality assurance" within the NHS. Proposals for medical audit were outlined in the NHS Review Working Paper $6,{ }^{2}$ and detailed arrangements for general practice audit were made explicit in a health circular. ${ }^{3}$ These included the setting up of a medical audit advisory group (MAAG) in every family health services authority (FHSA) in England and Wales, with similar arrangements in Scotland, based on health boards. A MAAG is "accountable to the FHSA for the institution of regular and systematic medical audit in which all practitioners take part ... the objective is the participation of all practices by April 1992"3 (our italics).

Early in 1990 the $\mathrm{DOH}$ financed pilot projects in four FHSAs to explore alternative approaches to implementing medical audit. Liverpool FHSA, through its MAAG, adopted a "facilitation" model and used various methods to encourage grass roots audit activity among general practices in the city ${ }^{4}$; a graduate "audit administrator" ( $\mathrm{MH})$ was recruited to support the project. The work of all four pilot studies relied heavily on the theoretical basis of medical audit, to which general practice has made significant contributions. ${ }^{5-7}$ Renewed interest induced by the NHS reforms was evident in the publication of two key books, ${ }^{89}$ while the North of England study of standards and performance in general practice ${ }^{10}$ confirmed that standard setting and audit can be effective both as educational activities and as agents of change.

Thus by 1990 there existed a theoretical model, several pilot projects exploring the proposed arrangements, and a timetable to establish medical audit as an integral part of general practice. However, medical audit had not found its way formally into the undergraduate curriculum in medical schools. This university department took the opportunity provided by its involvement in the local $\mathrm{DOH}$ pilot project to introduce audit into its undergraduate medical teaching, in the form of a one week course for students in their first clinical (third) year.

Project work in general practice was already part of the undergraduate medical course in Liverpool. In the previous five years it had evolved from a teacher oriented mass population survey into an exercise in which students chose the topic for their work in small groups. An innovatory step was to invite local general practitioners to propose practice based audit topics. Students continued to choose which of these to pursue and were then able to modify the proposals to meet their learning needs.

There are about 150 students in each year of the Liverpool course, so that each audit
Correspondence to: Dr Campion 
course involves 50 students for one week in December, April, and July. The July set are at the end of their second year ( and of their first clinical term). The December and April sets are correspondingly five and nine months further into the course.

\section{Subjects and methods}

Bids from general practitioners - About two months before the project week itself letters were sent to all general practices in the Liverpool FHSA area inviting them to submit a bid for student involvement in audit in the forthcoming project week and enclosing a structured form for completion (see figure below). Not all proposals were accepted: those which seemed to be unclear or unsuitable on educational grounds were either rejected or modified after discussion with the general practitioner (GP) concerned. A total of 18 practices took part in the three weeks of the first year of the scheme: 10 only once, three twice, and five in all three weeks.

The course began with a presentation defining medical audit and explaining the audit cycle. The box (right) contains an extract from the course booklet, which all students received.

The presentation explained the relation between the full cycle and the activity of the student project week: the students aimed at working through stages 1 to 4 , and may critically evaluate the chosen standard but were unlikely to see changes being implemented. They were, nevertheless, encouraged to make recommendations for change.

Numbers of students attending - For this part of the clinical course the students are divided into three groups of about 50. Attendance at the course was a requirement for being "signed up", and was virtually complete on the first and last days. The amount of time students spent working on the audit project

Reply form: please return by 11 th March to the Department of General Practice.

Practice

Contact person

stamp:

Telephone No:

1 What area of general practice do you propose to audit?

2 What questions would you like to address with the students?

3 What methods might be appropriate for the students to use?

4 Having collected the data, what standard(s) would you use to make comparisons?

5 Any other points you wish to make in support of your bid?

6 Please outline for the benefit of the students, how they may reach your practice by public transport (a map, if you have one, would also help).

Audit bid form

\section{Audit cycle}

1 Define what it is you wish to look at, in terms of structure, process, or outcome (explained later in the booklet)

2 Define a standard against which you can compare practice

3 Carry out audit

4 Compare with standard or evaluate in some other way

5 Critically examine the chosen standard and, if appropriate, make changes to clinical practice

6 Go to (3) and repeat cycle

7 Return to (1)

was left to them and to peer pressure from within each small group.

Choice of project - Students chose their projects from details of the practices and their audit proposals displayed in a seminar room and were expected to form groups of between three and six according to the project they had chosen. This process, though chaotic, seems to be the least formal and most democratic way of matching projects with students.

Supervision - Having chosen the project, each group met with a member of staff from the department of general practice to consider the ideas put forward by the practice and to discuss alternative approaches. Then, usually by the early afternoon of the first day, the groups travelled to their practices and began work with the GPs. Supervision by staff of the department is largely determined by the students: those students who feel adequately supported by the practice in which they are working may not seek any help; others, if they have problems which the practice cannot solve, may contact members of the department during the week. Some staff make firm arrangements to see a representative of the group(s) at intervals during the week, to monitor progress and to help with analysis of data and presentation of results.

Topics - The audit topics were initiated by practices but could be modified by the students in discussion with the practices and their supervisor. The box overleaf lists the audit topics addressed by student groups in 1990-1.

Presentation - The week culminates in a plenary "symposium" at which each group presents its work. The practices are invited, and most send a representative. The Liverpool FHSA, which funds a modest prize for the best project, has been represented by its chairman at each of these symposia; also present are the administrative assistant of the MAAG and a member of the faculty board of the local faculty of the Royal College of General Practitioners, which also funds a prize. All members of the academic staff independently rated each project on a scale of 0 to 5 (apart from the project they supervised) in the following dimensions:

- Difficulty of chosen audit task

- Validity of data gathered

- Appropriateness of chosen standards 


\section{Topics for audit projects in general practice}

Fuly 1990

Frequent attenders (in depth study of a small number)

Epilepsy (quality of care)

Asthma (quality of care)

Cardiovascular risk (extent to which recorded)

Hormone replacement therapy and the menopause (rate of treatment)

Repeat prescriptions for over the counter drugs for minor illness

Patient satisfaction with increased consultation length

Patient satisfaction with a new appointment system

Minor surgery

Health promotion clinic for cardiovascular risk factors

December 1990

Quality of terminal care

Patients' perceptions of health education

GP contacts with nursing home patients

Minor surgery

Repeat prescribing (2)

Health promotion clinics

Well woman clinic

Well baby clinic

Contraception: patients' knowledge and attitudes

\section{April 1991}

Study of proportion of list seen in one year

Long term benzodiazepine prescribing

Health promotion clinic

Prescribing and monitoring of digoxin

Evaluation of a practice employed counsellor

Alcohol: recording of problems, patient understanding

Asthma treatment

Asthma prevalence in records

Flow of patients in waiting area

Treatment of opiate drug users

- Clarity of presentation

- Level of teamwork displayed by the group

- Importance of findings to the practice.

These ratings are totalled to give each project a score out of 30 , and prizes are awarded at the end of the symposium to the members of the two highest scoring projects.

\section{Results}

STUDENT AUDITS

At one extreme, students used in depth unstructured interviews to explore the medical and social histories and associated emotions of a very small group of patients (six) identified by the GP as being frequent attenders at the practice, with the aim of assessing the extent of unmet need. Most projects combined some scrutiny of records (manual or computer) with either interviews or questionnaires to patients and sometimes to health professionals as well. Patient satisfaction surveys were commonly combined with observation of structures and processes, such as intervals between appointments or clinic procedures. Thus in an audit of minor surgery, patients were telephoned for their perceptions of the service and of the outcome, and the records were scrutinised for evidence of the histological findings and clinical outcomes.

The study of frequent attenders showed the extent of hidden emotional conditions in these patients, with two significant consequences: the GP, having been made aware of an unmet need, employed a counsellor (whose work became the subject of a later audit) and the students discovered how much "hidden" information could be elicited by the simple techniques of listening and facilitating. This audit, more notably than some, clearly led to change and, appropriately, re-audit.

Studies of the adequacy of asthma inhaler technique, in which students saw patients at home and observed their use of inhalers, or of epilepsy care, in which the students interviewed patients at home or at the surgery and assessed their quality of life, generated outcome data, which, by comparison with standards derived from published work, led to recommendations for change. The audit of minor surgery in one practice resulted in the students appreciating the range of procedures available in general practice and the practice discovering that it was not sending all specimens for examination nor recording outcome in the case notes.

SURVEY OF GPS

After the first complete year of projects a questionnaire was sent out to all practices which had participated. Those which had been involved more than once received only one questionnaire. The two page questionnaire sought responses about the practice's perception of the ease of "bidding," the extent its proposal was modified by the students after the joint planning process; the length of the project; the value of the final reporting session, if practices had attended it; the value of feedback, if any; and whether the project had resulted in changes in the practice. Finally, practices were asked whether they would consider having another group of students and were invited to comment freely on the findings of the survey.

Eighteen questionnaires were sent out and 15 were returned. Twelve practices found the process of submitting a bid "not difficult," and six reported that the final project had changed substantially after the shared planning with the students; but only one indicated no change at all. About half the practices thought that the duration of the project was about right, and half that it was too short. Twelve were represented at the final session when the students presented their results; all but two of them found the session of high value to them. Only nine of the 15 had received feedback, written or oral, from the students, and others indicated that they had expected it. The perceived value of the feedback was high for five, intermediate for three, and low value for one respondent. Ten practices had made changes as a result of the audits, four being described as substantial changes, one minor but gradual, and the remaining five minor. 
All the responding GPs stated that they would repeat the exercise, eight as it was, six with modifications. Negative but constructive comments included "group too large," "task difficult," "time too short," and "students more junior than expected"; while positive comments were "very valuable to practice," "very worthwhile," "good learning process for students," and "more projects like this would help to change the practice."

\section{Discussion}

Despite two decades of discussion about audit as a professional obligation the reality in 1990 was that it had failed to become an integral part of general practice in the United Kingdom. Once the $\mathrm{DOH}$ provided in the medical audit advisory groups the resources for a supportive infrastructure and had, through pilot studies, shown the effectiveness of these arrangements ${ }^{41-13}$ an entirely new situation was created.

In this situation an academic department of general practice has two principal responsibilities: to ensure that medical students are prepared for audit in their professional life and to help colleagues in general practice, and their patients, to benefit from involvement in audit. We believe that these two responsibilities can both be met, in part, in the course outlined here. Undergraduate medical education is notoriously slow in adapting to the changing realities of professional life, and Liverpool was fortunate in having an existing and flexible segment of time in the curriculum under the control of this department. For colleagues in general practice, academic departments are seen as natural allies in addressing the technical challenges of audit, and this role is reflected in the composition of MAAGs. ${ }^{3}$ Both parties, then, have learning needs; the major challenge was to design a course which evenhandedly addressed the needs of students and colleagues.

Our experience of teaching audit by means of a "project," rather than by didactic lectures, confirms the view that audit is a subject, par excellence, for experiential learning. ${ }^{14}$ Moreover, at the outset of their clinical training medical students are keen to adopt adult learning methods. ${ }^{15}$ This entails, for students, greater choice and self motivation and, for teachers, a facilitative role. Supervision presents departmental teachers with several challenges: to help a small group of students to work effectively as a team; to provide support without the wish to control; and sometimes to show students and colleagues that much learning has occurred during an audit which for technical reasons appeared unsuccessful.

Colleagues in general practice are familiar with the elements of the audit cycle and recognise the need to focus audit activity on a specific element of their work. The bidding process we have incorporated into this course is designed to ensure that practices select topics which are both realistic, given the timescale, and sufficiently challenging to merit student involvement. Although during the first year of the course we reduced the number of successful bids to match roughly the number of student subgroups, there is no reason why a wider choice should not be on offer. From the end of 1991 practices in adjacent areas outside the city of Liverpool were invited through their local MAAGs to bid for student involvement in audit.

The requirement that each subgroup present its findings to a symposium at the end of the week means that students must organise their data and consider ways of communicating them to an audience quickly and effectively. Fortunately, a medical informatics course run from the department during the first year in Liverpool has equipped students with computing skills; the department provides access to computers with appropriate database and graphics software.

The rating of what was achieved on the basis of these presentations, while potentially divisive, did not prove to be so. Prizes are seen by staff and students as motivators of effective team work and as a demonstration of the importance placed on audit by the royal college and the FHSA; in absolute terms the prizes are small - for example, enabling the "winners" to enjoy a modest meal together.

The results of our survey of the practices and the high level of attendance at the symposia by GPs and students are encouraging. They tend to support the view that in this format the course is meeting the learning needs of colleagues and students and, in modest ways, changing the service available to patients. The commitment of most students was very high - it was not unusual during the week of the course for students to be working well into the evenings. Particularly important from the perspective of primary care is the extent to which student subgroups became effective teams, with shared ideas, diversified roles, and division of labour. We believe that opportunities for teamwork are all too rare in a curriculum supposedly preparing most students for the role of clinician in the NHS.

The length of the course is seen both as a handicap and a strength: one week is a very short time to conduct an audit and present the findings even if the task is shared among five or six students. On the other hand, this constraint probably forces practices to focus on realistic projects and motivates students to work effectively. Although most student subgroups complete a satisfactory pilot project (and thereby demonstrate the strengths or weaknesses of the chosen method, or both), some produce completed work of outstanding quality. Two examples emerged in which student involvement with the practice continued subsequently - namely, the audit of frequent attenders and a study of patient satisfaction.

Overall, we commend this approach to colleagues in other academic departments (and not only those of general practice) as an effective exercise in joint undergraduate and postgraduate professional learning. The format of the course seemed to lend itself to 
other areas of common learning need, including in general practice: research methodology, ethical analysis, resource management, and intersectoral collaboration in health care. The prerequisites seem to be that established doctors recognise a learning need shared with undergraduates and are able to provide relevant experience. The role of the department would then be to create a loosely structured course which enables doctors and students to derive shared learning from the selection and analysis of experience.

We thank all the participating practices for their contribution, and Hilary Seedhouse, department of general practice, for secretarial help.

1 Secretaries of State for Health, Wales, Northern Ireland, and Scotland. Working for patients. London: HMSO, 1989. (Cmnd 555.)

2 Secretaries of State for Health, Wales, Northern Ireland and Scotland. Medical Audit Working Paper 6. London: HMSO, 1989

3 Department of Health, Health Service Development Medical audit in family practitioner services. London: $\mathrm{DoH}$ 1990. (HC (FP) (90)8.)
4 Liverpool Medical Audit Advisory Group. Medical audit advisory group: one year's experience of a pilot project in University of Liverpool, 1991. (Occasional paper No 2.

5 Sheldon MG. Medical audit in general practice. London: Royal College of General Practitioners, 1982. (Occasional paper No 20.)

6 Royal College of General Practitioners. Quality in Practice Bulletins. No 1-16. London: RCGP, 1984-5.

7 Royal College of General Practitioners. Quality in general practice. London: RCGP, 1985. (Policy statement No 2.)

8 Hughes J, Humphreys C. Medical audit in general practicea practical guide to the literature. London: King's Fund

9 Marinker M, ed. Medical audit and general practice. London: $B M F, 1990$.

10 Centre for Health Services Research, Newcastle upon Tyne. North of England study of standards and performance in general practice: an overview of the study. Newcastle upon Tyne: CHSR, 1991.

11 Newcastle Medical Audit Advisory Group. Learning by doing - the chairman's report on a pilot study. Newcastle upon Tyne: Newcastle MAAG, 1990.

12 Northumberland Family Health Services Authority. Medical audit for Northumberland general practice. A report Medical audit for Northumberland general practice. A repor to the Northumberland FHSA of a pilot project in the formation of a medical audit advisory group. East

13 Lincolnshire Family Practitioner Committee. Medical audit in primary care - a strategy for Lincolnshire. The report of the medical audit project team. Lincoln: Lincolnshire Family Health Services Authority, 1990.

14 Kolb DA. Experiential learning: experience as a source of learning and development. Englewood Cliffs, New Jersey: Prentice Hall, 1984.

15 Brookfield SD. Understanding and facilitating adult learning. Milton Keynes: Open University Press, 1986. 